\title{
TLR9: an important molecule in the fight against hepatitis B virus
}

\author{
Aziz Shahrakyvahed, ${ }^{1}$ Javad Sanchooli, ${ }^{2}$ Nima Sanadgol, ${ }^{3,4}$ \\ Mohammad Kazemi Arababadi, ${ }^{5}$ Derek Kennedy ${ }^{6}$
}

${ }^{1}$ Department of Nursing, Faculty of Nursing and Midwifery, Zabol University of Medical Sciences, Zabol, Iran ${ }^{2}$ Department of Immunology, Faculty of Medicine, Zabol University of Medical Sciences, Zabol, Iran

${ }^{3}$ Department of Biology, Faculty of Science, University of Zabol, Zabol, Iran

${ }^{4}$ Faculty of Pharmacy and Pharmaceutical Science Research Center (PSRC), Tehran University of Medical Sciences (TUMS), Tehran, Iran ${ }^{5}$ Immunology of Infectious Diseases Research Center, Rafsanjan University of Medical Sciences, Rafsanjan, Iran ${ }^{6}$ School of Natural Sciences, Eskitis Institute for Drug Discovery, Griffith University Nathan, Queensland, Australia

\section{Correspondence to} Dr Mohammad Kazemi Arababadi, Immunology of Infectious Diseases Research Center, Rafsanjan University of Medical Sciences, Rafsanjan 7718665179, Iran;

dr.kazemi@rums.ac.ir

Received 10 August 2013

Revised 19 April 2014

Accepted 5 May 2014

\section{CrossMark}

To cite: Shahrakyvahed $A$, Sanchooli J, Sanadgol N, et al. Postgrad Med J 2014;90:396-401.

\section{ABSTRACT}

Hepatitis B virus (HBV) is the most prevalent infectious agent that can induce severe liver disease. Patients infected with long-term HBV, including chronic, asymptomatic and occult forms, cannot clear HBV from infected hepatocytes completely. It is not clear why some people can clear the infection while others cannot. Furthermore, the main mechanisms responsible for progression of the infections are not fully understood. It has been hypothesised that differences in genetic and immunological parameters between patients and subjects who successfully clear HBV infections are responsible for inducing the long-term forms of the infection. Previous investigations showed that Toll-like receptors (TLRs) play important roles in immune responses, especially innate immunity, against viral infections, including hepatitis $B$. TLR9 detects intracellular viral dsDNA, which results in the activation of an immune response against HBV. However, defects in this system may result in an attenuated response ultimately leading to long-term HBV infections. Targeting the defects in TLR9 or reactivating the downstream pathways that are normally switched on by TLR9 in response to HBV infection is a new approach to the treatment of long-term HBV infection. However, the pathways and defects seen in patients with long-term HBV need to be thoroughly explored before therapeutics can be applied in the clinical setting. Furthermore, the apparently multigenic nature of long-term HBV infection suggests that treatment of patients may need to be personalised.

\section{INTRODUCTION}

Hepatitis $\mathrm{B}$ virus (HBV) is the most prevalent infectious agent of the liver and induces hepatitis $\mathrm{B}$ in humans. $^{1-3}$ Patients infected with long-term HBV, such as those with chronic, asymptomatic and occult HBV infection, cannot clear HBV from either hepatocytes or serum samples. ${ }^{4} 5$ Previous studies have proposed that prolonged-term HBV infections might be the main causes of cirrhosis of the liver and hepatocellular carcinoma (HCC). ${ }^{6} 7$ However, the main mechanisms responsible for development of the prolonged forms of HBV infections are yet to be identified and it has been suggested that genetic and immunological differences between patients and subjects who successfully clear HBV infections (the clearance group) may be the main reasons for persistent forms of the infection. ${ }^{1} 5{ }^{8}$ Alternatively, the infecting virus might carry 'escape' mutations helping it to avoid detection by the host. Escape mutations with HBV are discussed elsewhere. ${ }^{9}$ Toll-like receptors (TLRs) are the main intracellular/extracellular immune cell receptors that play key roles in pathogen-associated molecular pattern or 'PAMP' (table 1) recognition. TLRs convert pathogen recognition by the activation of immune responses against viruses, including hepatitis B. ${ }^{10}$

TLR/PAMP interactions induce several immune cell functions, ranging from phagocytosis, ${ }^{11}$ migration, ${ }^{12}$ nicotinamide adenine dinucleotide phosphate (NADPH) oxidase activation $^{13}$ to inflammatory cytokine expression. ${ }^{14}$ Accordingly, TLR9 activation leads to the expression of inflammatory cytokines, major histocompatibility complexes and homing molecules, via the detection of intracellular viral dsDNA in a MYD88-dependent manner. ${ }^{15}$ Therefore, impaired expression of TLR9 may result in attenuated immune responses against HBV infection. Based on the fact that the immune system of patients infected with prolonged-term HBV cannot completely clear HBV from hepatocytes, ${ }^{16-18}$ it appears that these patients have defects in some parameters of their immune systems. TLR9 plays an important role in the detection and induction of immune responses against viral infection, and alterations in TLR9 expression may result in survival of $\mathrm{HBV}$ in the infected liver of patients with long-term HBV. Therefore the role of TLR9 in HBV recognition and subsequent host immune responses needs to be clarified because a complete understanding of the response to this infection may lead to therapeutic agents directed towards the reactivation of an immune response in those patients defective in this pathway. Figures 1 and 2 present the TLR9 signalling pathways which result in activation of immune responses. The figures also highlight the mechanisms used by HBV to suppress TLR9 signalling and thereby escape the normal immune response. These pathways provide insight into how treatments might target the reactivation of the immune system so that a patient could clear the infection.

\section{HISTORY, GENOMIC LOCATION AND STRUCTURE OF TLR9}

TLR9 was first cloned and determined as a receptor for unmethylated CpG-DNA, bacterial, viral and parasite DNA in $2000 .{ }^{19}$ The gene encoding this receptor is located on $3 \mathrm{p} 21.3$ and the protein encoded by the gene is highly conserved and plays a key role in pathogen recognition and activation of immune responses. This molecule is a type I transmembrane protein, with its N-terminal, which consists of leucine-rich repeats (LRRs), on the outside of the membrane. This is followed by a hydrophobic transmembrane domain and a cytoplasmic Toll/interleukin 1 receptor (TIR) domain 
Table 1 Abbreviations used within the article and descriptions of their terminology

\begin{tabular}{|c|c|c|}
\hline Abbreviation & Full terminology & Brief description \\
\hline AP-1 & Activator protein 1 & A transcription factor which is activated after TLRs/ligand interaction \\
\hline BCL-2 & B-cell lymphoma 2 & An pro-apoptotic molecule \\
\hline CCLs & CC ligands & A cluster of chemokines \\
\hline CXCLs & CXC ligands & A cluster of chemokines \\
\hline CTL & Cytotoxic T lymphocyte & T lymphocyte which kills infected and cancer cells \\
\hline DNMT-1 & DNA methyltransferase 1 & A protein in the TLR signalling pathway \\
\hline HBsAg & Hepatitis B surface antigen & Surface protein of HBV \\
\hline HBV & Hepatitis B virus & A DNA virus which infects the liver \\
\hline $\mathrm{HCC}$ & Hepatocellular carcinoma & Cancer of liver \\
\hline Interleukins & ILs & A subclass of cytokines which are used by a host to enhance immune responses \\
\hline IRAKs & Interleukin-1 receptor associated kinases & Signalling molecules in the TLRs activation pathway \\
\hline IRF7 & Interferon regulatory factor 7 & A transcription factor which is activated after TLRs/ligand interaction \\
\hline JAK1 & Janus kinase 1 & Cytokine receptor signalling molecules \\
\hline LRRs & Leucine-rich repeats & Extracellular domain of TLRs \\
\hline MAPK & Mitogen-activated protein kinase & An intracellular signalling pathway which results in activation of AP-1 \\
\hline MYD88 & Myeloid differentiation primary response & An adaptor molecule in TLRs signalling \\
\hline NADPH & Nicotinamide adenine dinucleotide phosphate & A coenzyme which is used in anabolic reactions \\
\hline NF- $\mathrm{KB}$ & Nuclear factor kappa-light-chain-enhancer of activated B cells & A transcription factors which is activated after TLRs/ligand interaction \\
\hline PBMC & Peripheral blood mononuclear cell & Immune cells within peripheral blood, often considered as the white blood cells \\
\hline STAT3 & Signal transducer and activator of transcription 3 & Cytokine receptor signalling molecules \\
\hline TAK1 & Transforming growth factor $b$-activated kinase 1 & A protein in the TLR signalling pathway \\
\hline TIR & Toll/interleukin 1 receptor & Intracellular domain of TLRs \\
\hline TRAF6 & TNF receptor associated factor & A protein in the TLR signalling pathway \\
\hline
\end{tabular}

TLR, Toll-like receptor; TNF, tumour necrosis factor.

(figure 1). Although the TLR9 receptor is considered to be an extracellular receptor, it is also found on intracellular membrane organelles, including the endosome and the endoplasmic reticulum (ER). ${ }^{20}$ Once activated, the TLR9/ligand complex triggers the activation of various intracellular signalling molecules and transcription factors to elicit an immune response to the recognised pathogen.

\section{TLR9 LIGANDS}

Antigens are ligands that are carried or presented by an invading pathogen and are specifically recognised by receptors on host immune cells. Once an antigen or ligand has bonded to a receptor it would normally activate an appropriate response to the invading organism. Antigens presented by different pathogens specify the type of host response and are important factors to consider when developing possible treatments for a disease. $\mathrm{B} / \mathrm{K}$-type and $\mathrm{A} / \mathrm{D}$-type are two subtypes of CpG-oligodeoxy nucleotides (CpG-ODNs) which are considered as TLR9 ligands, ${ }^{21}$ and these types of ligand are present in HBV. The $\mathrm{B} /$ K-type CpG-ODNs induce $\mathrm{B}$ cell proliferation and dendritic cell (DC) maturation, whereas the A/D-type CpG-ODNs induce type I interferons in plasmacytoid dendritic cells (pDCs). ${ }^{22}$ In addition, DNA without CpG motifs can also be considered as an active ligand for TLR9. ${ }^{23}$ Therefore, TLR9 recognises both DNA with and without CpG motifs. Furthermore, TLR9 also recognises the genomic DNA of bacteria and viruses. For example, it has been shown that TLR9 recognises genomic DNA of Mycobacterium tuberculosis, ${ }^{24}$ Brucella $^{25}$ and Streptococcus pneumoniae ${ }^{26}$ to induce immune responses against the bacteria. Additionally, previous studies have shown that DNA viruses, such as HBV, have unmethylated CpG motifs and are considered ligands for TLR9. Several studies demonstrated that herpes simplex virus (HSV) types 1 and $2,{ }^{27}$ mouse cytomegalovirus (MCMV) ${ }^{27} 28$ and adenovirus ${ }^{28}$ are detected by TLR9 in pDCs and lead to the production of interferon $\alpha$ and other cytokines, thus initiating the immune response to the recognised pathogen. TLR9 ligands will need to be considered in future treatments designed for vaccination or treatment of HBV.

\section{THE INTRACELLULAR SIGNALLING PATHWAY OF TLR9}

Once a ligand has bound to a receptor and activated a downstream pathway, a normal immune response to the pathogen is expected. However, if the pathway is disturbed, attenuated or defective the pathogen can proceed unhindered. Candidate treatments for long-term HBV infection need to consider which pathways are disrupted during HBV infection so that they can be reactivated. Previous studies showed that intracellular signalling of TLR9, like other TLRs, is MYD88 dependent. ${ }^{29}$ After TLR9/CpG-ODNs interaction, the TIR domains of TLR9 and MYD88 interact with each other. ${ }^{30}$ Activated MYD88 interacts with IRAK1 and IRAK4 via the death domain, which leads to recruitment of TRAF3 and TRAF6. ${ }^{31}$ This event activates TAK1, mitogen-activated protein kinase (MAPK), AP-1 and $\mathrm{NF}-\kappa \mathrm{B} .{ }^{32} \mathrm{33} \mathrm{NF}-\kappa \mathrm{B}$ is a transcription factor for several genes, including cytokines, chemokines, addressing and homing molecules as well as costimulatory molecules such as CD80 and CD86 and other molecules that will not be discussed here but are reviewed elsewhere. ${ }^{34}$ In addition, IRAK1 and TRAF3 directly and indirectly, respectively, activate IRF7, which plays a key role in the transcriptional activation of type I interferon. ${ }^{35}$ Expression of type I interferons are the first immune responses against viral infections including $\mathrm{HBV}^{36}$ The typical signalling pathway is shown in the figure 1. 
Figure 1 TLR9 and its intracellular signaling pathway.

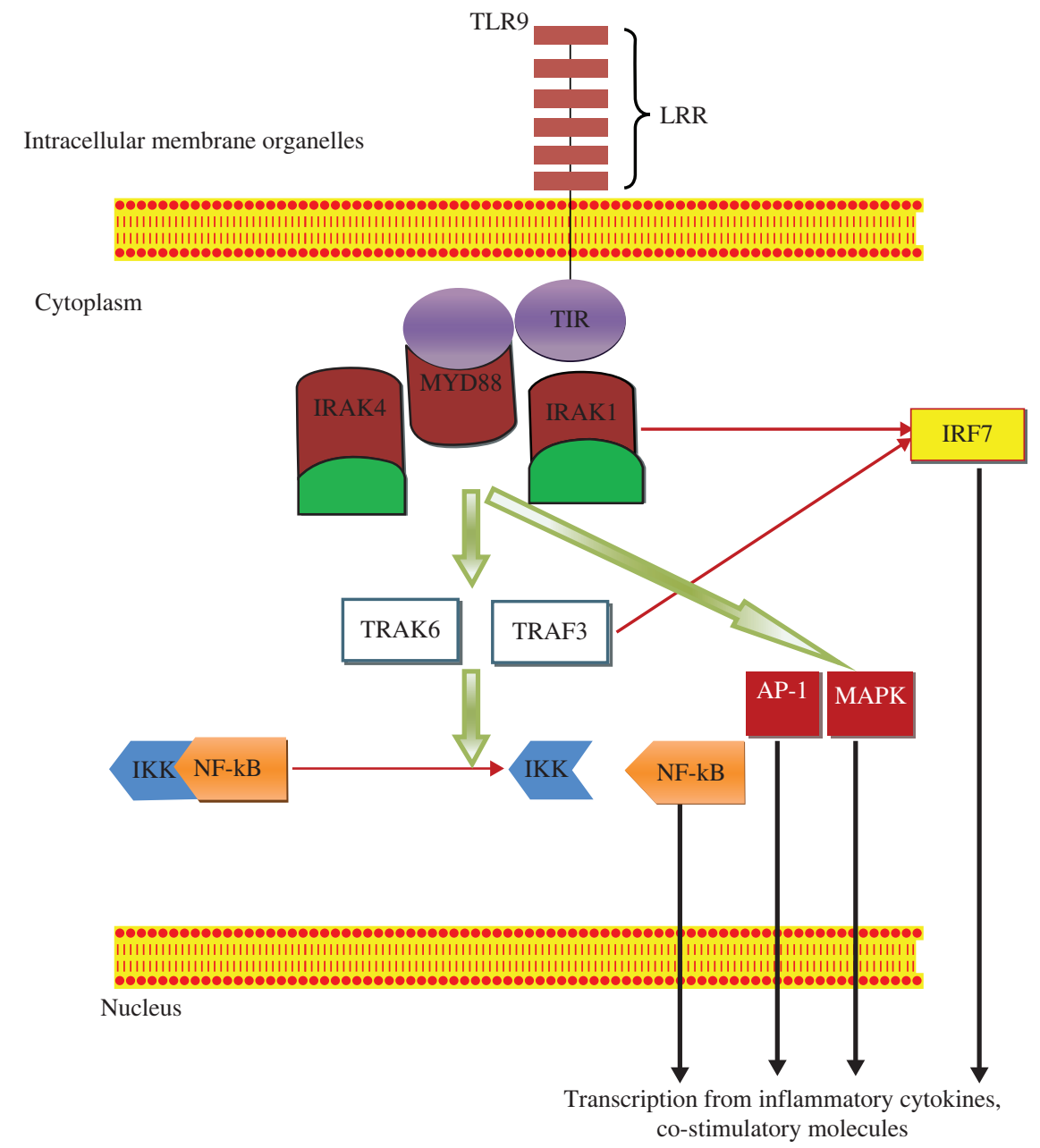

\section{HBV-DNA can be recognised by TLR9}

TLR9/HBV-DNA interactions are normally the main mechanism leading to activation of immune cells. For instance, Cui and Diao, ${ }^{37}$ reported that introducing HBV-DNA to pDCs led to activation of the NF-кB, MAPK and IRF7 molecules, which resulted in secretion of type I interferons and inflammatory cytokines and maturation of DCs. Additionally, studies on primary primate hepatocytes showed that TLR9/ligand interactions led to the production of inflammatory cytokines. ${ }^{38}$ Wu $e t a l^{39}$ also demonstrated that TLR9 activation induces production of antiviral cytokines in myeloid DCs derived from the liver of C57/BL6 wild-type mice. These findings highlight how TLR9 activation, by the recognition of foreign DNA, is one of the main mechanisms used by a host to recognise HBV and activate an immune response.

\section{Expression of TLR9 and its signalling molecules is disrupted} in patients infected with chronic HBV (CHB)

Patients infected with long-term HBV cannot eradicate the virus from hepatocytes completely and this may be caused by a defect in TLR9 expression or signalling. Accordingly, previous studies showed that the expression of TLR9, MYD88, IRAK1, IRAK4, TRAF3, IRF7, NF-אB and TRAF6 in the circulating while blood cells of peripheral blood mononuclear cells (PBMCs) taken from patients infected with $\mathrm{CHB}$ were significantly decreased in comparison with healthy controls. ${ }^{29}$ Martinet et al ${ }^{40}$ found that pDCs from patients infected with $\mathrm{CHB}$ displayed defective responses to stimulation with TLR9 ligands and were unable to induce cytolytic activity of NK cells. This result was supported in a study by $\mathrm{Xu}$ and colleagues, ${ }^{41}$ which introduced TLR9 ligands to pDCs and found impaired type I interferon responses. Ratnam and colleagues reported that the stimulated NK cells of patients infected with $\mathrm{CHB}$ had an impaired interferon $\gamma$ response to TLR9 ligands in comparison with controls. ${ }^{42}$ Another study showed that mRNA levels of TLR9 were negatively correlated with serum levels of liver enzymes, while, positively associated with $\mathrm{HBV}$ viral load in patients with $\mathrm{CHB}{ }^{43}$ Zhou et $a l^{44}$ also reported that expression levels of TLR9 were significantly decreased in patients with CHB. In parallel with these results, Xie and colleagues showed that expression levels of TLR9 mRNA and protein levels were decreased in pDCs of patients with $\mathrm{CHB}$ in comparison with healthy controls. ${ }^{45}$ The current literature suggests that TLR9 expression and function are compromised in the immune cells taken from patients with prolonged forms of hepatitis B infection and this may be important in understanding how infection persists in those patients.

\section{HBV interferes with expression and function of TLR9 and its} signalling molecules

Several factors influence TLR9 expression in patients with prolonged forms of hepatitis B, and this attenuates the host's ability to raise an immune response to the infection. Shi et al ${ }^{46}$ showed that HBsAg inhibited TLR9 expression on pDCs either by direct 
effects on pDCs or indirectly through the induction of monocytes to release interleukin 10 (IL-10) (figure 2). IL-10 leads to downregulation of several inflammatory molecules via the JAK1/ STAT3 signalling pathway, ${ }^{47}$ hence, this mechanism may be responsible for downregulation of TLR9 by the indirect effects of HBsAg (figure 2). Xu et $a l^{48}$ also reported that HBsAg can suppress TLR9 transcription in pDCs. However, a complete picture of the mechanisms explaining the direct effect of HBsAg on the decreased expression of TLR9 in pDCs has yet to be clarified. Vincent and colleagues also showed that HBV led to downregulation of TLR9 at the transcriptional level in pDCs and B cells in which TLR9 mRNA and protein levels were decreased. ${ }^{49}$ The researchers showed that HBV can affect TLR9 activity by blocking the MYD88-IRAK4 axis. ${ }^{49}$ Interestingly, another study showed that HBeAg-positive patients displayed impaired interferon $\alpha$ production in response to CpG-ODNs by pDCs compared with HBeAg-negative patients and healthy controls. ${ }^{50}$ Thus, it seems that HBeAg can also inhibit TLR9 activation via unknown mechanisms. Hirsch et al, ${ }^{51}$ also demonstrated that $\mathrm{HBV}$ can lead to decreased expression of TLR9 and interferon $\alpha$ in pDCs via interactions with the regulatory receptors of pDCs. Downregulation of TLR9 expression was also reported in patients with $\mathrm{CHB}$ with high HBV-DNA copy numbers in comparison with patients with low HBV-DNA copy numbers. ${ }^{44}$ In addition, the existence of neutralising $\mathrm{CpG}$ motif sequences within the DNA genome of HBV genotypes A to $\mathrm{H}$ may also be considered as plausible mechanisms for the inhibitory effects on TLR9-immune activation. ${ }^{49}$ The data presented in these studies overwhelmingly suggest that HBV-DNA may directly decrease expression of TLR9 in immune cells. Regardless of the mechanism, the data suggest that infection by HBV can reduce the efficacy of the TLR9 responses and this may tip the balance in favour of the virus in those patients who cannot clear the infection through alternative immune responses.

\section{Host genetic and epigenetic variations are responsible for downregulation of TLR9 and its signalling molecules}

The genotype of the host may also present a potential candidate for decreased expression of TLR9 in the immune cells of patients with prolonged forms of hepatitis B. Although it may not be possible to identify the genetic changes, it may be possible to assess their affects by looking at the diseases associated with long-term HBV infection. For instance, Jia et $a l^{52}$ reported that the polymorphisms within the TLR9 gene were significantly associated with HBV-related liver cirrhosis. Wu et $a l^{30}$ also found that the polymorphisms within the promoter region of TLR9 were significantly associated with earlier spontaneous HBeAg sero conversion. In addition, an association of TLR9 with HBV-related hepatocellular carcinoma has been reported by Liu et al. ${ }^{53}$ They showed that mRNA of DNMT-1 and BCL-2 were raised when hepatocytes were stimulated with HBV-DNA. ${ }^{53}$ It also appears that TLR9 can play a crucial role in the immunopathogenesis of hepatitis B. Previous studies demonstrated that micro-RNAs play critical roles in regulation of gene expression, ${ }^{54}$ and hence, $\mathrm{HBV}$ or host encoded
Figure 2 The mechanisms used by HBV to suppress TLR9 signaling pathway.

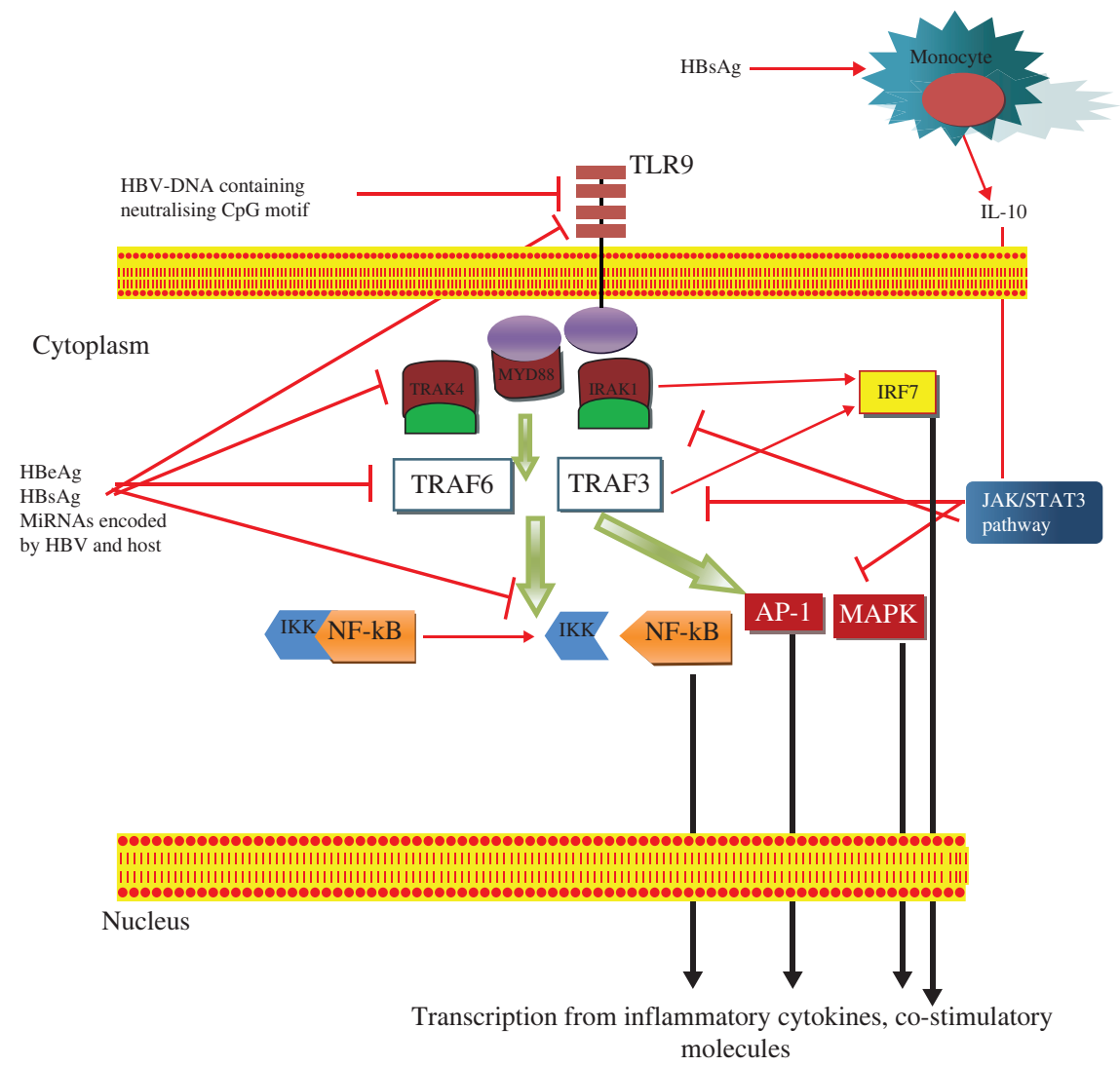

Polymorphisms within

TLR9 and its signaling molecule genes
Transcription from TLR9 and its signaling molecule genes 
micro-RNAs may affect TLR9 expression and its signalling molecules in these patients. Furthermore, the author of this review article also hypothesises that, in addition to the factors and mechanisms reported above, epigenetics may regulate expression of genes required for complete clearance of HBV, and altered expression may contribute to the downregulation of TLR9 in patients infected with prolonged HBV and associated diseases.

\section{CONCLUSIONS}

The accumulated data highlight the key role of TLR9 in the induction of humoral and cellular immune responses against hepatitis B. Accordingly, it is not surprising that patients infected with prolonged HBV are unable to express suitable levels of TLR9 and its signalling molecules to induce expression of essential inflammatory factors, including proinflammatory cytokines, chemokines and costimulatory molecules that are required for the eradication of the HBV infection. Future treatments could focus on strategies which can upregulate the expression of TLR9 and its signalling molecules as a way of reactivating the immune responses and facilitating the eradication of HBV from patients infected with prolonged HBV. Additionally, the results suggest that TLR9 ligands can be considered as a powerful target for adjuvants to use in $\mathrm{HBV}$ vaccination, especially in patients who fail to respond to conventional vaccination. Future studies can be directed to discovering new ligands or to enhance current ligands for TLR9 to improve immune responses against HBV in patients with prolonged HBV. Alternatively, adjuvants designed to stimulate TLR9 responses could be used to improve humoral immune responses, especially in non-responding vaccinated subjects. Overall, several approaches need to be taken. Patients who do not respond to current vaccinations need to be identified and in these cases vaccinations that enhance TLR9 signally can be considered. In patients with long-term HBV the immune system needs to be activated so that the patient can clear the infection. Future treatments may focus on activating TLR9 and its downstream targets to kick-start the immune system. The best way to fight long-term HBV infection would be to use the patient's own immune system and this, in turn, would limit the secondary diseases, such as cirrhosis of the liver and hepatocellular carcinoma, typically seen in these patients.

\section{Main messages}

- Immunological surveillance in patients with long-term hepatitis B virus (HBV) infection does not detect the hepatitis $B$ virus

- The genes encoding for components of the immune system in patients with long-term HBV may carry mutations that do not allow them to recognise the virus particles.

- Some patients in whom HBV is recognised may lack the ability to respond owing to mutations in genes required for a complete response to the virus particles.

- Mutations within some strains of HBV may allow them to avoid detection by the host immune system.

- HBV harbours mechanisms that interfere with the host's cytokine signalling pathways that normally participate in a patient's response to the virus.

- Toll-like receptor 9 (TLR9) represents the nexus between the HBV pathogen and the host immune system and this recognition pathway does not function in patients with long-term HBV.

\section{Current research questions}

- Can the immune system of patients with long-term hepatitis $B$ virus (HBV) be reactivated to recognise the pathogen?

- Can we remodulate the cytokine responses of patients with long-term HBV so that they can successfully clear the virus?

- Are there mechanisms that we can use, outside the host immune system, which can eradicate the pathogen from patients with long-term HBV?

- Can TLR9 be used as a target in treatments for long-term HBV infection?

\section{Key references}

- Ayoobi F, Hassanshahi G, Zainodini N, et al. Reduced expression of TRIF in chronic HBV infected Iranian patients. Clin Res Hepatol Gastroenterol 2013;37:491-5.

- Arababadi MK, Ahmadabadi BN, Kennedy D. Current information on the immunological status of occult hepatitis B infection. Transfusion 2012;52:1819-26.

- Sajadi SMA, Mirzaei V, Hassanshahi G, et al. Decreased expressions of TLR9 and its signaling molecules in chronic HBV infected patients. Arch Path Lab Med 2013;137:1674-9.

Contributors AS, JS and NS collected the data regarding the roles of TLR9 in hepatitis B. MKA provided the main idea and wrote the main part of the article. DK edited the text to improve the English and scientific conclusion.

Funding This project was granted by the Rafsanjan University of Medical Sciences. Competing interests None.

Provenance and peer review Not commissioned; externally peer reviewed.

\section{REFERENCES}

1 Assar S, Arababadi MK, Ahmadabadi BN, et al. Occult hepatitis B virus (HBV) infection: a global challenge for medicine. Clin Lab 2012;58:1225-30.

2 Ayoobi F, Hassanshahi G, Zainodini N, et al. Reduced expression of TRIF in chronic HBV infected Iranian patients. Clin Res Hepatol Gastroenterol 2013;37:491-5.

3 Khorramdelazad H, Hassanshahi G, Nasiri Ahmadabadi B, et al. High serum levels of TGF-beta in Iranians with chronic HBV infection. Hepat Mon 2012;12:e7581.

4 Chan HL, Jia J. Chronic hepatitis B in Asia-new insights from the past decade. J Gastroenterol Hepatol 2011;26(Suppl 1):131-7.

5 Arababadi MK, Pourfathollah AA, Jafarzadeh A, et al. Association of exon 9 but not intron 8 VDR polymorphisms with occult HBV infection in south-eastern Iranian patients. J Gastroenterol Hepatol 2010;25:90-3.

6 Mendy ME, Welzel T, Lesi OA, et al. Hepatitis B viral load and risk for liver cirrhosis and hepatocellular carcinoma in the Gambia, West Africa. J Viral Hepat 2009;27:27.

7 Michielsen P, Ho E. Viral hepatitis B and hepatocellular carcinoma. Acta Gastroenterol Belg 2011;74:4-8.

8 Ahmadabadi BN, Hassanshahi G, Arababadi MK, et al. The IL-10 promoter polymorphism at position -592 is correlated with susceptibility to occult HBV infection. Inflammation 2012;35:818-21.

9 Zare-Bidaki M, Ayoobi F, Hassanshahi G, et al. Mutations within the HBC gene of the hepatitis B virus: a study from Iranian patients. Clin Lab 2014;60:9-21.

10 Khvalevsky E, Rivkin L, Rachmilewitz J, et al. TLR3 signaling in a hepatoma cell line is skewed towards apoptosis. J Cell Biochem 2007;100:1301-12.

11 Hirayama T, Tamaki Y, Takakubo Y, et al. Toll-like receptors and their adaptors are regulated in macrophages after phagocytosis of lipopolysaccharide-coated titanium particles. J Orthop Res 2011;29:984-92.

12 Nguyen-Pham TN, Lim MS, Nguyen TA, et al. Type I and II interferons enhance dendritic cell maturation and migration capacity by regulating CD38 and CD74 that have synergistic effects with TLR agonists. Cell Mol Immunol 2011:8:341-7.

13 Bae YS, Lee JH, Choi SH, et al. Macrophages generate reactive oxygen species in response to minimally oxidized low-density lipoprotein: toll-like receptor 4- and 
spleen tyrosine kinase-dependent activation of NADPH oxidase 2. Circ Res 2009;104:210-18, 21p following 8.

14 Imani Fooladi AA, Mousavi SF, Seghatoleslami S, et al. Toll-like receptors: role of inflammation and commensal bacteria. Inflamm Allergy Drug Targets 2011:10:198-207.

15 Jia $N$, Xie Q, Lin L, et al. Common variants of the TLR9 gene influence the clinical course of HBV infection. Mol Med Report 2009;2:277-81.

16 Arababadi MK, Ahmadabadi BN, Kennedy D. Current information on the immunological status of occult hepatitis B infection. Transfusion 2012;52:1819-26.

17 Khorramdelazad H, Hassanshahi G, Ahmadabadi BN, et al. High serum levels of TGF- $\beta$ in Iranians with chronic HBV infection. Hepat Mon 2012;12:e7581.

18 Arababadi MK, Pourfathollah AA, Jafarzadeh AA, et al. Serum levels of interleukin (IL)-10 and IL-17A in occult HBV infected south-east Iranian patients. Hepat Mon 2010;10:31-5.

19 Hemmi H, Takeuchi O, Kawai T, et al. A Toll-like receptor recognizes bacterial DNA. Nature 2000;408:740-5.

20 Latz E, Schoenemeyer A, Visintin A, et al. TLR9 signals after translocating from the ER to CpG DNA in the lysosome. Nat Immunol 2004;5:190-8.

21 Kumagai Y, Takeuchi O, Akira S. TLR9 as a key receptor for the recognition of DNA. Adv Drug Deliv Rev 2008;60:795-804.

22 Hemmi H, Kaisho T, Takeda K, et al. The roles of Toll-like receptor 9, MyD88, and DNA-dependent protein kinase catalytic subunit in the effects of two distinct $\mathrm{CpG}$ DNAs on dendritic cell subsets. J Immunol 2003;170:3059-64.

23 Kandimalla ER, Bhagat L, Li Y, et al. Immunomodulatory oligonucleotides containing a cytosine-phosphate-2'-deoxy-7-deazaguanosine motif as potent toll-like receptor 9 agonists. Proc Natl Acad Sci USA 2005;102:6925-30.

24 Bafica A, Scanga CA, Feng CG, et al. TLR9 regulates Th1 responses and cooperates with TLR2 in mediating optimal resistance to Mycobacterium tuberculosis. J Exp Med 2005;202:1715-24.

25 Copin R, De Baetselier P, Carlier Y, et al. MyD88-dependent activation of B220-CD11 b+LY-6C+ dendritic cells during Brucella melitensis infection. J Immunol 2007:178:5182-91.

26 Lee KS, Scanga CA, Bachelder EM, et al. TLR2 synergizes with both TLR4 and TLR9 for induction of the MyD88-dependent splenic cytokine and chemokine response to Streptococcus pneumoniae. Cell Immunol 2007;245:103-10.

27 Krug A, French AR, Barchet W, et al. TLR9-dependent recognition of MCMV by IPC and $D C$ generates coordinated cytokine responses that activate antiviral NK cell function. Immunity 2004;21:107-19.

28 Zhu J, Huang $X$, Yang Y. Innate immune response to adenoviral vectors is mediated by both Toll-like receptor-dependent and -independent pathways. I Virol 2007:81:3170-80

29 Sajadi SMA, Mirzaei V, Hassanshahi G, et al. Decreased expressions of TLR9 and its signaling molecules in chronic HBV infected patients. Arch Pathol Lab Med 2013;137:1674-9.

$30 \mathrm{Wu} J \mathrm{~F}$, Chen $\mathrm{CH}, \mathrm{Ni} \mathrm{YH}$, et al. Toll-like receptor and hepatitis B virus clearance in chronic infected patients: a long-term prospective cohort study in Taiwan. J Infect Dis 2012;206:662-8.

31 Chang WJ, Toledo-Pereyra LH. Toll-like receptor signaling in liver ischemia and reperfusion. J Invest Surg 2012;25:271-7.

32 Szatmary Z. Molecular biology of toll-like receptors. Gen Physiol Biophys 2012;31:357-66.

33 Li X, Jiang S, Tapping RI. Toll-like receptor signaling in cell proliferation and survival. Cytokine 2010;49:1-9.
34 Tuosto L. NF-kappaB family of transcription factors: biochemical players of CD28 co-stimulation. Immunol Lett 2011;135:1-9.

35 Barber GN. Cytoplasmic DNA innate immune pathways. Immunol Rev 2011;243:99-108.

36 Alsharifi $\mathrm{M}$, Lobigs $\mathrm{M}$, Regner $\mathrm{M}$, et al. Type I interferons trigger systemic, partial lymphocyte activation in response to viral infection. J Immunol 2005;175: 4635-40.

37 Cui GY, Diao HY. Recognition of HBV antigens and HBV DNA by dendritic cells. Hepatobiliary Pancreat Dis Int 2010;9:584-92.

38 Lucifora J, Vincent IE, Berthillon P, et al. Hepatitis B virus replication in primary macaque hepatocytes: crossing the species barrier toward a new small primate model. Hepatology 2010;51:1954-60.

39 Wu J, Lu M, Meng Z, et al. Toll-like receptor-mediated control of HBV replication by nonparenchymal liver cells in mice. Hepatology 2007:46:1769-78.

40 Martinet J, Dufeu-Duchesne T, Bruder Costa J, et al. Altered functions of plasmacytoid dendritic cells and reduced cytolytic activity of natural killer cells in patients with chronic HBV infection. Gastroenterology 2012;143:1586-96 e8.

$41 \mathrm{Xu} N$, Yao HP, Lv GC, et al. Downregulation of TLR7/9 leads to deficient production of IFN-alpha from plasmacytoid dendritic cells in chronic hepatitis B. Inflamm Res 2012;61:997-1004.

42 Ratnam DT, Sievert W, Visvanathan K. Natural killer cells display impaired responses to toll like receptor 9 that support viral persistence in chronic hepatitis B. Cell Immunol 2012;279:109-15.

43 Wang K, Liu H, He Y, et al. Correlation of TLR1-10 expression in peripheral blood mononuclear cells with chronic hepatitis B and chronic hepatitis B-related liver failure. Hum Immunol 2010;71:950-6.

44 Zhou J, Huang Y, Tian D, et al. Expression of toll-like receptor 9 in peripheral blood mononuclear cells from patients with different hepatitis $B$ and $C$ viral loads. J Huazhong Univ Sci Technolog Med Sci 2009;29:313-17.

45 Xie Q, Shen HC, Jia NN, et al. Patients with chronic hepatitis B infection display deficiency of plasmacytoid dendritic cells with reduced expression of TLR9. Microbes Infect 2009;11:515-23.

46 Shi B, Ren G, Hu Y, et al. HBsAg inhibits IFN-alpha production in plasmacytoid dendritic cells through TNF-alpha and IL-10 induction in monocytes. PLOS ONE 2012;7:e44900.

47 Liu WH, Liu JJ, Wu J, et al. Novel mechanism of inhibition of dendritic cells maturation by mesenchymal stem cells via interleukin-10 and the JAK1/STAT3 signaling pathway. PLOS ONE 2013;8:e55487.

48 Xu Y, Hu Y, Shi B, et al. HBsAg inhibits TLR9-mediated activation and IFN-alpha production in plasmacytoid dendritic cells. Mol Immunol 2009;46:2640-6.

49 Vincent IE, Zannetti C, Lucifora J, et al. Hepatitis B virus impairs TLR9 expression and function in plasmacytoid dendritic cells. PLOS ONE 2011;6:e26315.

50 Woltman AM, Op den Brouw ML, Biesta PJ, et al. Hepatitis B virus lacks immune activating capacity, but actively inhibits plasmacytoid dendritic cell function. PLOS ONE 2011:6:e15324.

51 Hirsch I, Caux C, Hasan U, et al. Impaired Toll-like receptor 7 and 9 signaling: from chronic viral infections to cancer. Trends Immunol 2010;31:391-7.

52 Jia N, Xie Q, Lin L, et al. Common variants of the TLR9 gene influence the clinical course of HBV infection. Mol Med Rep 2009;2:277-81.

53 Liu X, Xu Q, Chen W, et al. Hepatitis B virus DNA-induced carcinogenesis of human normal liver cells by virtue of nonmethylated CpG DNA. Oncol Rep 2009;21:941-7.

54 Gurtan AM, Sharp PA. The role of miRNAs in regulating gene expression networks. J Mol Biol 2013;425:3582-600. 


\section{PM TLR9: an important molecule in the fight against hepatitis $B$ virus}

Aziz Shahrakyvahed, Javad Sanchooli, Nima Sanadgol, et al.

Postgrad Med J 2014 90: 396-401

doi: 10.1136/postgradmedj-2013-132309

Updated information and services can be found at:

http://pmj.bmj.com/content/90/1065/396.full.html

\section{These include:}

References This article cites 54 articles, 8 of which can be accessed free at: http://pmj.bmj.com/content/90/1065/396.full.html\#ref-list-1

Email alerting
service

Receive free email alerts when new articles cite this article. Sign up in the box at the top right corner of the online article.

Notes

To request permissions go to:

http://group.bmj.com/group/rights-licensing/permissions

To order reprints go to:

http://journals.bmj.com/cgi/reprintform

To subscribe to BMJ go to:

http://group.bmj.com/subscribe/ 